\title{
Complementary Therapies That Are Used For The Relief of Dysmenorrhea Among Zagazig Technical Health Institute Students
}

\author{
Sanaa Ali Nour \\ Professor of Obstetric \& Gynecological Nursing, \\ Faculty of Nursing, Zagazig University \\ Amina S. Gonied \\ Assistant Professor of Obstetric \& Gynecological Nursing \\ Faculty of Nursing, Zagazig University \\ Manal A. Ali \\ Assistant Prof. of Rheumatology \& Rehabilitation \\ Faculty of Medicine, Zagazig University \\ Nagah F. Ali , \\ Assistant lecturer of Obstetric. \& Gynecological Nursing \\ Faculty of Nursing, Zagazig University
}

\begin{abstract}
The aim of this study was conducted to evaluate the impact of complementary therapies on relieving dysmenorrhea among students at Zagazig Technical Health Institute. The subjects of this study included all female students (721) Tools used to collect data: Visual analogue scale, Pre and post evaluation sheet of students' knowledge and a follow up sheet. A self - learning booklet was designed by the researcher and distributed as a guide to students for complementary therapies. The main Results showed that the prevalence rate of dysmenorrhea was $71.0 \%$ among students, and that there were statistical significant improvements in most characteristics of menstruation as well as physical \&psychological symptoms associated to dysmenorrhea, pain degree, pain site, daily activities, duration of pain, days of absenteeism , amount of menstrual blood flow and type of blood loss in all three groups .TENS group achieved the most noticeable improvement followed by exercise and acupressure .Based on the results of this study this study complementary therapies be more widely used and recommended by health care providers.
\end{abstract}

Keywords: Primary dysmenorrhea - Exercise - TENS - Acupressure. 


\section{Introduction:}

Primary dysmenorrhea means menstrual pain without pelvic pathology occurring with ovulatory menstrual cycles; usually begins during adolescence and occurs in women with normal pelvic anatomy. ${ }^{(1)}$

Accordingto Lethaby(2007) dysmenorrheal pain may occur with menses or precede menses by 1 to 3 days. It tends to peak 24 $\mathrm{h}$ after onset of menses and subside after 2 to 3 days. It is usually sharp but may be cramping, throbbing, or a dull, constant ache; it may radiate to the legs. Headache, nausea, constipation or diarrhea, lower back pain, and urinary frequency are common; vomiting occurs occasionally. (2) According to Chantler (2008) the prevalence rates of primary dysmenorrhea were as high as $90 \%$ while $10 \%$ of menstruating women have severe dysmenorrhea which is accompanied by labor like pain, with supra pubic cramping and sometimes with nausea, vomiting and diarrhea. This pain leads to absence from school or work and reduced women's life quality. ${ }^{(3)}$

Complementary and alternative medicine is an established intervention modality within the contemporary and health care system. Because of $10 \%$ of women with dysmenorrhea don't respond to treatment with oral contraceptives and other medications to relieve menstrual pain and some women have contraindications to these medications, the dysmenorrhea can be treated with alternative therapies such as acupressure, exercises, and TransCutaneous Electrical nerve stimulation "TENS". Each of those modalities is thought to act by stimulating endogenous opiod pain modulating systems ${ }^{(4)}$

Acupressure as an ancient healing art that uses the fingers to press key points on the surface of the skin to stimulate the body's natural self-curative abilities. When these points are pressed, they release muscular tension and promote the circulation of blood and the body's life force to aid healing. Acupuncture and acupressure use the same points, but acupuncture employs needles, while acupressure uses the gentle but firm pressure of hands ${ }^{(5)}$

Trans-Cutaneous Electrical nerve stimulation "TENS" is defined as the application of electrical current through the skin for pain control. The TENS unit sends an electrical "signal" through the skin to 
the nerves. This signal feels like a warm comfortable tingling sensation which helps block out some of the other pain stimuli that are also reaching to the central nervous system ${ }^{(6)}$. TENS can serve as an adjutant therapy to conventional pharmacological agents in treatment of severe. Cases of dysmenorrhea by decreasing uterine ischemia ${ }^{(7)}$.

Exercises also minimize pain by helping to lower prostaglandin levels, through increasing vasodilatation and decreasing ischemia. It leads to the release of endogenous opiates, especially

beta-endorphins, which suppress prostaglandins. Simple exercises such as., aerobic exercises, knee chest position, breathing exercises, pelvic tilt, stretching exercises and pelvic floor exercises may be beneficial for relieving dysmenorrheal pain ${ }^{(8)}$ Nursing intervention is an integral component of nursing practice and a major concern for most nurses. The nurse plays a pivotal role in pain management through offering comfort measures and reassurance to relief anxiety. She can help women to use pain reduction methods including; acupressure, exercises, TENS that decreases the incidence of dysmenorrhea. The nurse can give 5information, encourage the positive attitudes towards dysmenorrhea, training and explain the safety and side effects of pain reduction methods ${ }^{(9)}$

\section{Aim of the study}

The aim of the study is to evaluate the impact of complementary therapies on the relief of dysmenorrhea among students in Zagazig Technical Health Institute.

\section{Research hypothesis}

The use of complementary therapies can reduce the incidence of primary dysmenorrhea among female students.

\section{Materials and method:}

Study design: A descriptive and a comparative intervention designs were used in carrying out this study.

Setting: The study was conducted at Zagazig Technical Health Institute.

\section{Subjects:}

The study included all female students (721) at Zagazig Technical Heath Institute to estimate the prevalence of primary dysmenorrhea and to describe the characteristics of their menstruation. Of those students, a simple random sample of 150 students who complained of primary dysmenorrhea were selected based on the following equation of using the range of complementary therapies between $75 \%$ 
and $95 \%$, and a power of $80 \% \& \alpha=0.05$, the minimal required sample size was found to be 47 for each group (increased to 50) so the total required sample size was 150 students. Those were randomly and equally assigned for the three groups of treatments.

First group: 50 female students used exercises such as; breathing exercise, pelvic tilt, kegel and aerobic exercise.

Second group: 50 female students used the TENS (high TENS were used, its frequency between 100-150 Hz; pulse width between 100-500 Ms, and its intensity between 12 and $30 \mathrm{~mA}$.

Third group: 50 female students to whom the acupressure technique was applied by using finger pressure to certain meridian points (SP6, Acupoint \#2, \#13, and \#15) on the body to relief pain.

\section{Tools of data collection:}

The following tools were used for data collection:

\section{- Tool 1. Structured interview sheet:}

Collect the basic data, it included the following

a) Socio-demographic data of the studied subject such as, social status, telephone number, height, and weight. The estimation of the body mass index (BMI) was measured according to the following equation BMI $=$ weight $/$ height ${ }^{2}$.

b) Menstrual characteristics such as; age at menarche, amount of blood loss which was measured according to the number of pads/day) rhythm, interval and the duration of menstruation, the onset of dysmenorrhea, any previous methods used to relieve dysmenorrheal pain and associated symptoms of dysmenorrhea.

c) Includes the impact of pain associated with menstruation on the student's physical, psychological health, student' daily activities and life style, absenteeism and the measures she used to manage this problem.

\section{Tool 2. Visual analogue scale}

According to Campbell $\left(1995^{)(10)}\right.$ a self reported device consisting of $10 \mathrm{~cm}$ straight line, which represented a continuum of pain intensity and had verbal anchors at opposite ends representing no pain, pain as bad as it can be. Pain intensity was evaluated by asking the girls to point on the line the number that represented the intensity of their pain. The scores corresponding to the pain intensity was as follows: - No pain (0), Mild pain (1 - 3), Moderate pain (4 - 5), Sever pain $(6-8)$, unbearable $(9-10)$. 
This tool was used before and after the application of acupressure, exercises, and transcutaneous electrical nerve stimulation (TENS).

\section{Tool 3. Pre and post evaluation sheet of} students' knowledge

- This sheet was used to assess students' knowledge in relation to anatomy of female genital organs, menstruation, dysmenorrhea and types of complementary therapy which were used in the study.

\section{Tool 4. Follow up sheet.}

A Follow up sheet was used by the student and researcher to record the intensity of pain after the application of the therapy. This was done after the first month, second and then after the third month.

\section{Method}

Once permission was granted to proceed with the study, the researcher started to collect data and implement the program of intervention according to the following way: The total number of the female students

enrolled at Zagazig Technical Health Institute at the beginning of October 2009 to April 2010 from grade I, II, were contacted and their number was 721 students. All these students received the structured interview sheet (Tool I) to estimate the prevalence of primary dysmenorrhea and student's menstrual characteristics. Out of those students who had dysmenorrhea(512), and 150 1students was selected randomly and divided equally into three groups, each group include 50 students. Group I used exercises; Group II used TENS and Group III used acupressure for relieving dysmenorrhea.

The purpose of the study was explained to each group. The pretest knowledge questionnaire was distributed and self administered, then used after the program implementation for post assessment. A Self Learning.The theoretical and training sessions were conducted, together with a demonstration for each technique was done by the researcher and re-demonstration was carried out by every student on the applied complementary therapy. The program consisted of 10 sessions for each group and the total time of sessions were 11 hours theoretical and 8 hours practices for each group. The numbers of students in each session were only 25 in order to facilitate learning process and allow every student to participate in training as well as ensuring adequate supervision. Two 
sessions were conducted weekly.

The first group ( I ) utilized exercises and was taught the benefits of exercises, types of exercises and procedures, the best time for practices, frequency /day. The student should start to practice exercise after or before menstruation from $1-3$ times daily .The student can choose the type of exercise which she can practice as shown in self learning booklet .

The second group (II) utilized TENS and was taught; its definition, action, advantage, disadvantage, precautions, sites of placing the electrodes of the apparatus, time of application, the guideline for the procedure. The TENS frequency between 100-150 Hz; pulse width between 150$500 \mathrm{~ms}$, and it's intensity between 12 and $30 \mathrm{~mA}$; it was automatically adjusted and was placed on the skin at the site of pain or near from it. This technique was applied for each subject for 10-30 minutes 3 times /day during dysmenorrhea for 3 menstrual cycles.

The third group (III) used acupressure and acquired the knowledge about its definition action, advantage, uses, precautions, acupressure points for dysmenorrhea, direction of pressure, and duration of pressure. The students apply acupressure on acupoints \#13 is located one palm width below the navel or two finger widths below the belly button; another point with similar effects can be found two thumb widths below this one. Acupoints \# 15 is located on the middle finger, just above the nail, on the side closest to the thumb. Acupoint\#5 (Sp6), located on the inside of the lower leg, one hand width (four fingers) above the tip of the ankle bone, on the back of the shin bone. Acupoints \# 2 is located two thumb widths from the largest crease on the inside wrist; the point is between the tendons in the middle of the wrist. Each subject was used acupressure for $\quad 10 \quad \min \quad 4$ times /day during dysmenorrhea for 3 menstrual cycles

\section{Statistical design. Scoring system}

Statistical analysis: After data collection, data was revised, coded and fed to statistical software SPSS version 16.

\section{a-Analysis of numeric data}

1. One-Sample Kolmogorov-Smirnov Test:

2. The Wilcoxon signed-rank test:

\section{b-Analysis of categorical data}

1. Pearson's chi square test:

Mont Carlo exact test and Fishers exact test: Cochran's Q test, the Friedman test. 
Results:

Figure (1): displays the prevalence of primary dysmenorrhea among the students at Zagazig Technical Health Institute. Almost three quarters of the students (71.0\%) were suffering from primary dysmenorrhea, while $29.0 \%$ had no dysmenorrhea.

Figure (2): shows that the mean score percent of knowledge regarding dysmenorrhea was increased in group I from $7.1 \%$ before the program to $78.6 \%$ post program. Additionally, the mean score percent of knowledge regarding dysmenorrhea was improved in GII from $14.3 \%$ pre-program to $85.7 \%$ post program and the same improvement applies to GIII from $14.3 \%$ to $82.1 \%$. The differences observed were highly significant $(\mathrm{P}=0.000)$.

Figure (3): displays the mean score percent of knowledge about the use of complementary therapy in the relief of dysmenorrhea before and after the intervention. It was obvious that there was a significant improvement in group I from $21.4 \%$ before the program to $92.9 \%$ post program. Also a significant difference in the mean score percent of knowledge $\left(\mathrm{P}=0.000^{*}\right)$ was observed among group II and III before and after the program in relation to the same aspect (group II from $10.0 \%$ to $80.0 \%$ and group III from $16.7 \%$ to $75.0 \%$ post program respectively).

Table(1): indicates that before the intervention, the majority of the students in the three study groups had reported that their daily activities were affected by dysmenorrhea, this percentage was reduced to $0.0 \%$ in the TENS, followed by $6.0 \%$ in the Acupressure and $8.0 \%$ in the exercise groups, after the third month of the application of the three techniques. In addition, there were no absent days and 0.0 $\%$ of the students in the TENS and acupressure groups resorted to any medication for the relief of dysmenorrhea.

Table (2): Shows a statistical significant relation between the severity of pain and the application of complementary therapies before and after the program. As seen, the majority of the students had heavy and unbearable pain before the program (80.0\% in GI, $68.0 \%$ in GII and $70.0 \%$ in GIII respectively). This was completely abolished in the TENS and Exercise groups after the third month of the application. Moreover, a sizable portion of the students were affected at all sites before the program, this also was improved 
in the TENS and Exercise groups but with no statistical significant difference.

Table (3): Clarified that, students in the Exercise group achieved the highest reduction regarding the duration of menstruation among the three studied groups at third month of application. Thus, students in the Exercise group had the duration 2 -3 days $(8.0 \%)$ before application and reached $74.0 \%$ after the third month of application. While the TENS group achieved the highest improvement regarding the light amount of blood loss $(96.0 \%)$ at third month of application. As for the type of blood loss, it was changed to fluids in $92.0 \%$ of the students, with no clotted blood in the TENS group. Differences observed were statistically significant $(\mathrm{P}=<0.05)$ 
Figure 1 . Prevalence of primary dysmenorrhea $(n=512)$

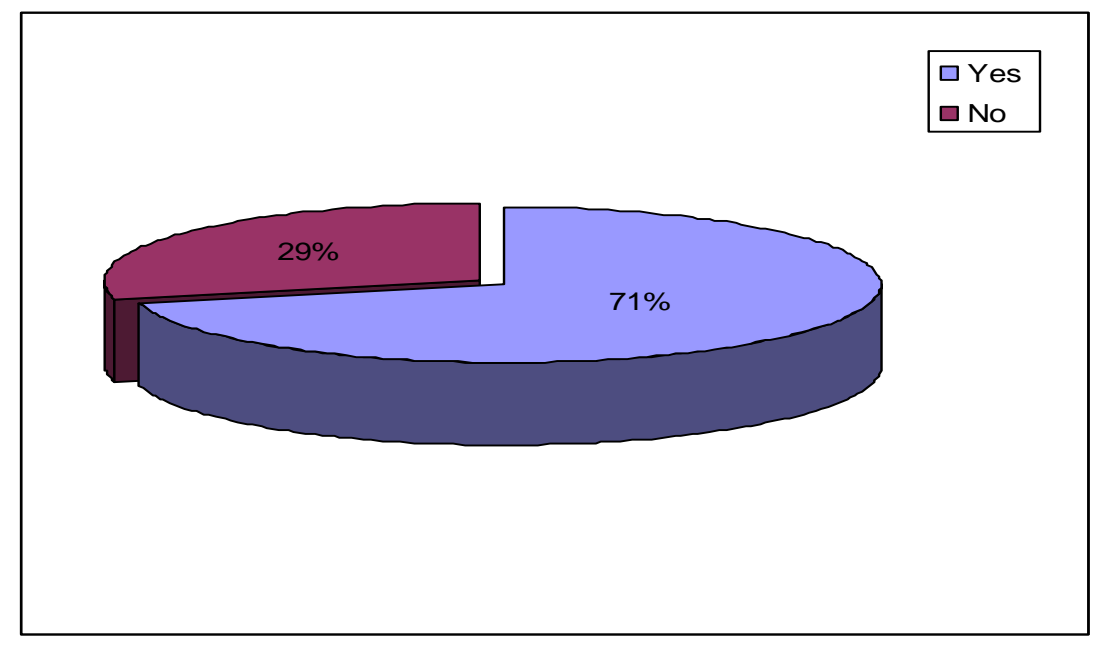

Figure (2): Presents mean score percent regarding knowledge of dysmenorrhea among the study groups before and after intervention $(n=150)$

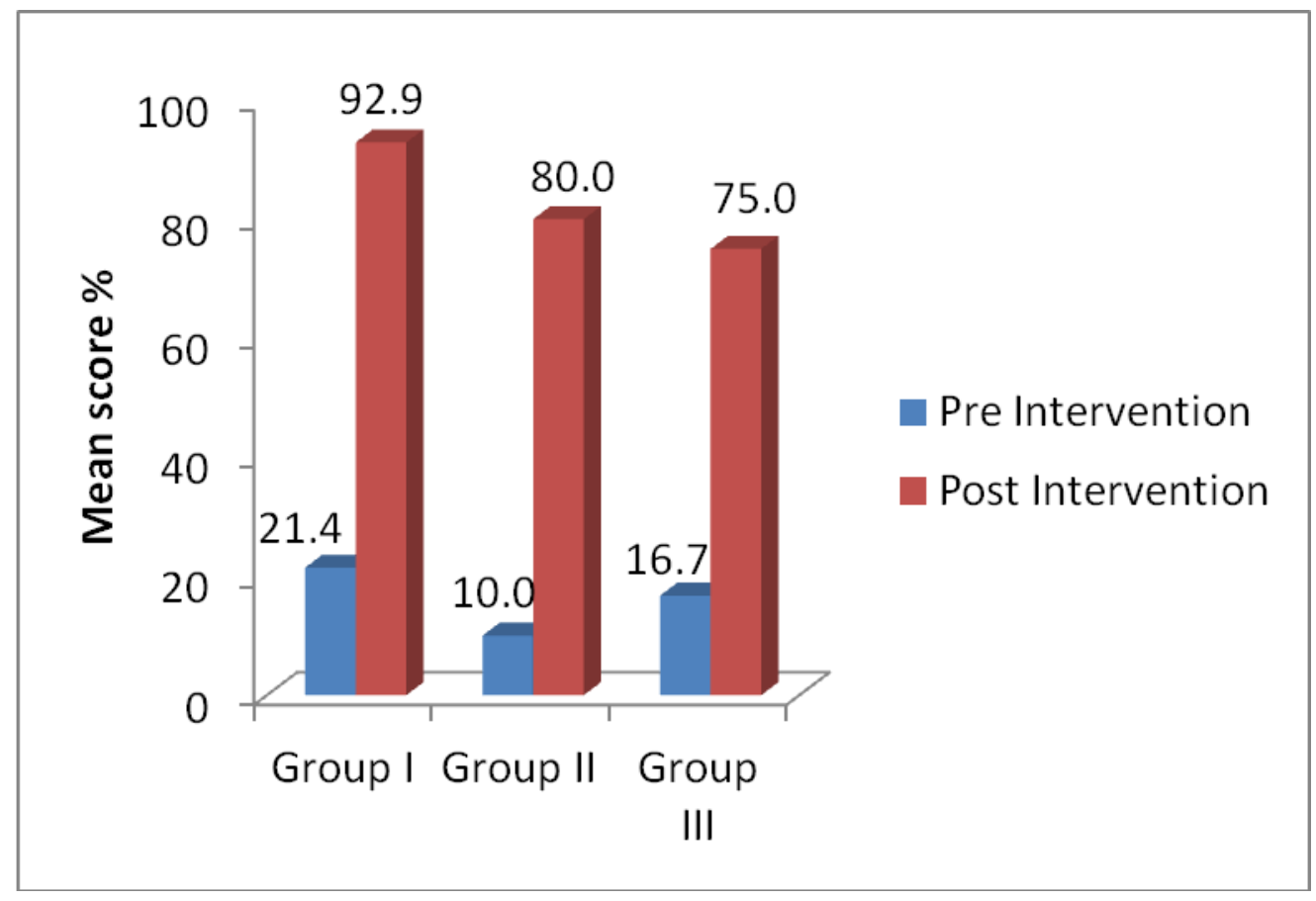


Figure (3): Presents mean score percent regarding knowledge of complementary therapy among the study groups before and after intervention $(n=150)$

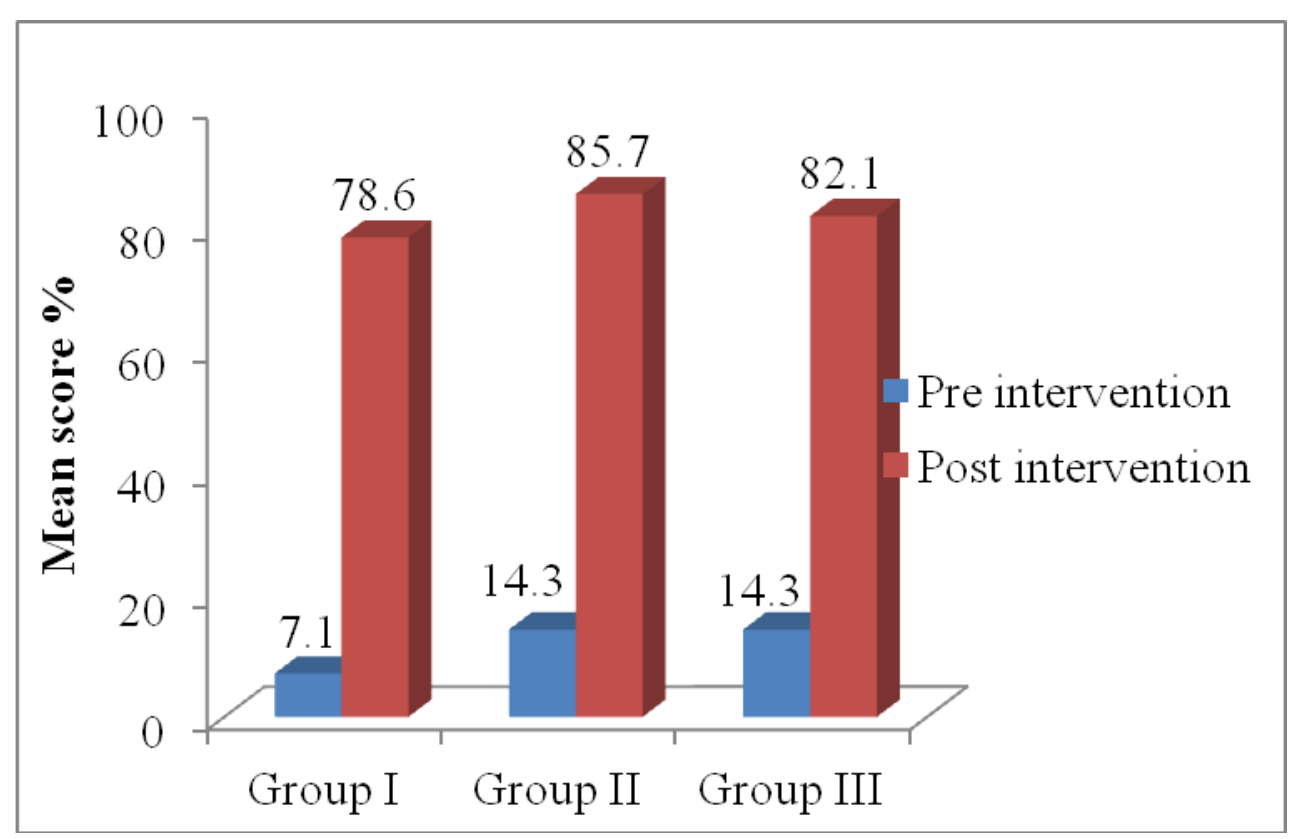


Table (1). Distribution of the study groups before and after the application of the three techniques according to the effect of pain on students' daily activities $(n=150)$.

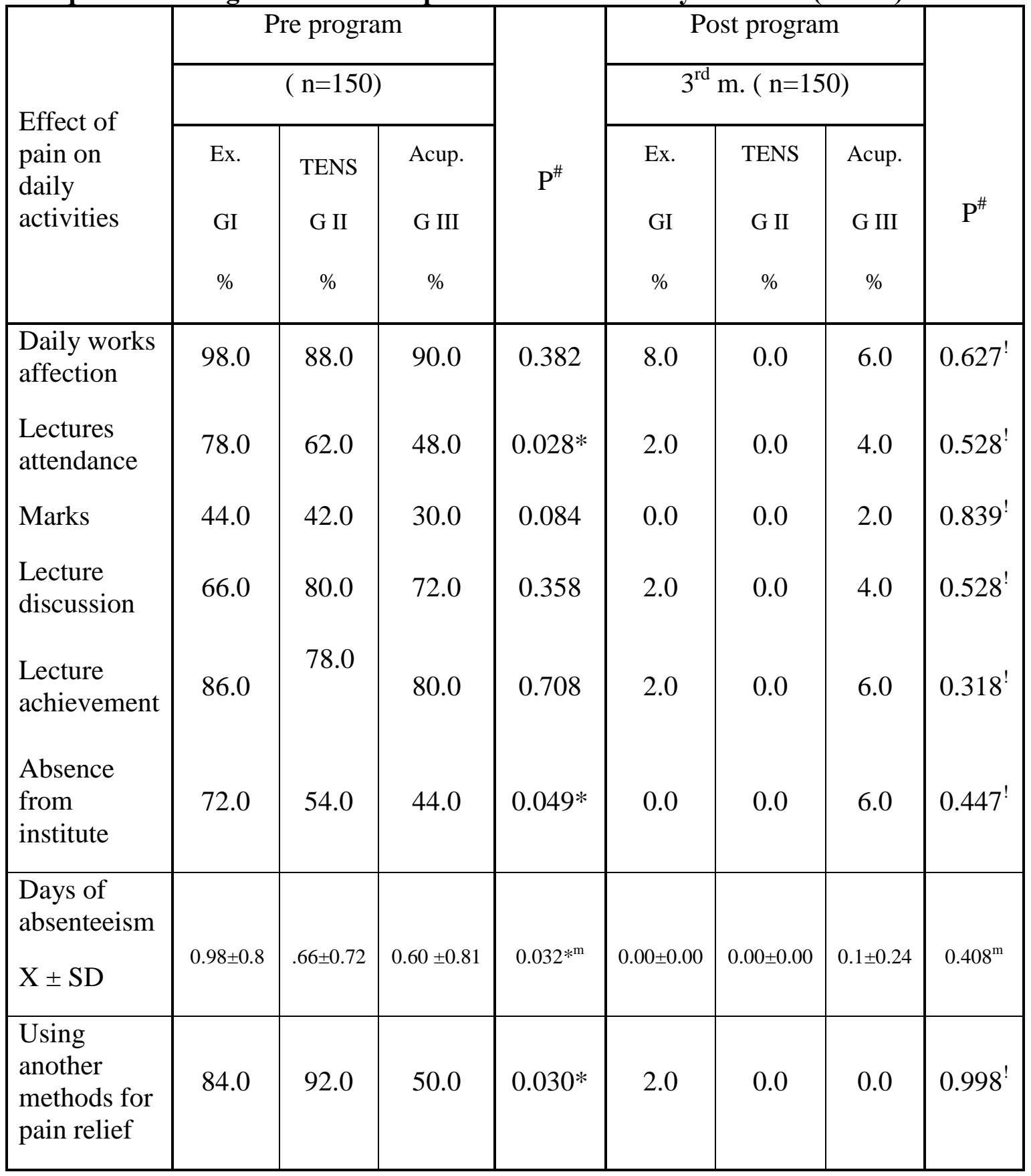

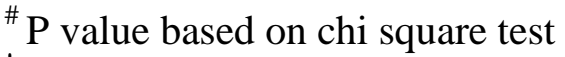

! P value based on Mont Carlo exact probability

More than one answer was allowed

${ }^{\mathrm{m}} \mathrm{P}$ value based on Mann-Whitney test 
$* \mathrm{P}<0.05$ (significant)

Table (2). Distribution of the study groups before and after the application of the three techniques according to pain degree and its site $(n=150)$.

\begin{tabular}{|c|c|c|c|c|c|c|c|c|}
\hline \multirow[b]{3}{*}{ Pain degree \&its site } & \multicolumn{3}{|c|}{ Pre program } & \multirow[b]{3}{*}{$\mathrm{P}^{\#}$} & \multicolumn{3}{|c|}{ Post program } & \multirow[b]{3}{*}{$\mathrm{P}^{\#}$} \\
\hline & \multicolumn{3}{|c|}{$(n=150)$} & & \multicolumn{3}{|c|}{$3^{\text {rd }} \mathrm{m} .(\mathrm{n}=150)$} & \\
\hline & $\begin{array}{c}\text { Ex. } \\
\text { GI } \\
\%\end{array}$ & $\begin{array}{c}\text { TENS } \\
\text { G II } \\
\%\end{array}$ & $\begin{array}{c}\text { Acup. } \\
\text { G III } \\
\%\end{array}$ & & $\begin{array}{c}\text { Ex. } \\
\text { GI } \\
\%\end{array}$ & $\begin{array}{c}\text { TENS } \\
\text { G II } \\
\%\end{array}$ & $\begin{array}{c}\text { Acup. } \\
\text { G III } \\
\%\end{array}$ & \\
\hline Pain degree & & & & & & & & \\
\hline None $(0)$ & 0.0 & 0.0 & 0.0 & & 8.0 & 0.0 & 2.0 & \\
\hline Slight $(1-3)$ & 0.0 & 6.0 & 6.0 & $0.104^{!}$ & 90.0 & 86.0 & 78.0 & $0.050 ! *$ \\
\hline Intermediate $(4-5)$ & 20.0 & 26.0 & 24.0 & & 2.0 & 14.0 & 18.0 & \\
\hline Heavy $(6-8)$ & 48.0 & 36.0 & 48.0 & & 0.0 & 0.0 & 2.0 & \\
\hline Unbearable $(>8)$ & 32.0 & 32.0 & 22.0 & & 0.0 & 0.0 & 0.0 & \\
\hline Pain site & & & & & & & & \\
\hline Lower abdomen & 10.0 & 16.0 & 16.0 & & 56.0 & 68.0 & 48.0 & \\
\hline Lower back & 4.0 & 0.0 & 8.0 & & 32.0 & 26.0 & 32.0 & \\
\hline Lower limbs & 16.0 & 22.0 & 8.0 & $0047 *$ ! & 0.0 & 6.0 & 4.0 & \\
\hline All sites & 44.0 & 40.0 & 32.0 & 0.071 & 0.0 & 0.0 & 10.0 & 0.011 \\
\hline Abdomen \&back & 18.0 & 14.0 & 16.0 & & 4.0 & 0.0 & 4.0 & \\
\hline Abdomen \&limbs & 8.0 & 8.0 & 20.0 & & 0.0 & 0.0 & 0.0 & \\
\hline No pain & 0.0 & 0.0 & 0.0 & & 8.0 & 0.0 & 2.0 & \\
\hline
\end{tabular}

${ }^{\#} \mathrm{P}$ value based on chi square test

More than one answer was allowed

! $\mathrm{P}$ value based on Mont Carlo exact probability 
$\mathrm{P}<0.05$ (significant)

Table (3). Distribution of the study groups before and after the application of the three techniques according to their menstrual characteristics $(n=150)$.

\begin{tabular}{|c|c|c|c|c|c|c|c|c|}
\hline \multirow{5}{*}{ Menstrual characteristics } & \multicolumn{3}{|c|}{ Pre program } & \multirow{5}{*}{$\mathrm{P}^{\#}$} & \multicolumn{3}{|c|}{ Post program } & \multirow{5}{*}{$\mathrm{P}^{\#}$} \\
\hline & \multicolumn{3}{|c|}{$(n=150)$} & & \multicolumn{3}{|c|}{$3^{\text {rd }} \mathrm{m} \cdot(\mathrm{n}=150)$} & \\
\hline & Ex. & TENS & Acup. & & Ex. & TENS & Acup & \\
\hline & GI & G II & GIII & & GI & GII & GIII & \\
\hline & $\%$ & $\%$ & $\%$ & & $\%$ & $\%$ & $\%$ & \\
\hline \multicolumn{9}{|l|}{ Duration of menstruation } \\
\hline 2 - days & 8.0 & 8.0 & 6.0 & \multirow{4}{*}{0.064} & 74.0 & 32.0 & 38.0 & \multirow{4}{*}{$0.021 * !$} \\
\hline 4 days & 56.0 & 62.0 & 48.0 & & 26.0 & 66.0 & 60.0 & \\
\hline $6-7$ days & 36.0 & 30.0 & 44.0 & & 0.0 & 2.0 & 2.0 & \\
\hline$>7$ days & 0.0 & 0.0 & 2.0 & & 0.0 & 0.0 & 0.0 & \\
\hline \multicolumn{9}{|c|}{$\begin{array}{l}\text { Amount of blood loss (No. of } \\
\text { pads/day) }\end{array}$} \\
\hline Light (pad) & 14.0 & 4.0 & 8.0 & \multirow[t]{3}{*}{0.308} & 72.0 & 96.0 & 82.0 & \multirow{3}{*}{$0.038 *$} \\
\hline Moderate $(2-3)$ & 72.0 & 80.0 & 80.0 & & 28.0 & 4.0 & 18.0 & \\
\hline Heavy (4) & 14.0 & 16.0 & 12.0 & & 0.0 & 0.0 & 0.0 & \\
\hline \multicolumn{9}{|l|}{ Type of blood loss } \\
\hline Fluids & 46.0 & 58.0 & 38.0 & 0.043 & 86.0 & 92.0 & 82.0 & \multirow{3}{*}{0.081} \\
\hline Clotted & 36.0 & 24.0 & 58.0 & $*$ & 0.0 & 0.0 & 10.0 & \\
\hline Both & 18.0 & 18.0 & 4.0 & & 14.0 & 8.0 & 8.0 & \\
\hline
\end{tabular}

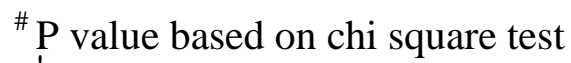

! $\mathrm{P}$ value based on Mont Carlo exact probability

$* \mathrm{P}<0.05$ (significant) 


\section{DISCUSSION:}

As for the prevalence of primary dysmenorrhea, the present study found that, out of 512 female students, almost three quarters of the students $(71.0 \%)$ were suffering from primary dysmenorrhea, while $29.0 \%$ had no dysmenorrhea. The high prevalence of dysmenorrhea in the present study is ascribed to the lack of student's knowledge about dysmenorrhea and the simplest techniques to cope with it. The present study nearly agrees with Hassin $\left(2002^{)(11)}\right.$ who found that, the prevalence of dysmenorrhea was $70.0 \%$ out of total 1000 students at the Faculty of Nursing, Mansoura University. Similarly Burnett (2005) $)^{(12)}$ and Singh et al ., $\left(2008^{)(13}\right)$ reported that, the prevalence rate of dysmenorrhea ranges between $28.0 \%$ and $71.7 \%$ and that primary dysmenorrhea affected approximately $73.83 \%$ out of total of 107 female medical students at Indian Medical College, department of physiology. In addition the present study coincides with Ali $(2004)^{(14)}$ who reported that, the prevalence dysmenorrhea was $85.0 \%$ out of the total of 470 students at the Faculty of Nursing at Elmania
University. Similarly, Polat et al. (2009) ${ }^{(15)}$ who mentioned that, the prevalence rate was $89.5 \%$ out of total of 1,266 female university students in Turkey. Furthermore the current study agrees with Unsal et al . $(2010)^{(16)}$ who reported that, the prevalence of dysmenorrhea was $72.7 \%$ among female students at Dumlupinar University, Kutahya, Health High School, Western Turkey. Recently, Shaban (2011) ${ }^{(17)}$ reported that, the prevalence rate of dysmenorrhea was $90.0 \%$ out of the total of 1400 students at the Faculty of Nursing, Tanta University. On the other hand, the present study disagrees with Abd ElHameed et al.(2011) ${ }^{(18)}$ who mentioned a high prevalence rate $(94.4 \%)$ of dysmenorrhea. Reasons for the variation in these estimates may be ascribed to the use of selected groups of women, and to the absence of a universally accepted method of defining dysmenorrhea, which was probably as greatly responsible for the disparity as the methods of collecting data, the study definition of dysmenorrhea, pain, and the study populations themselves) ${ }^{(19)}$ The current study proved that the 
complementary therapies were very effective in relieving dysmenorrheal pain especially TENS method followed by exercises and acupressure. This result matches with Wilson\&Murph(2002) ${ }^{(20)}$ and Lemcke et al., (2004) ${ }^{(21)}$ who reported that, exercise and TENS therapies are the most popular complementary therapies and that they are playing an important role in the relieving dysmenorrhea.

Although the three therapies achieved improvements in pain relieving in the present study, TENS therapy achieved the most remarkable improvement regarding physical symptoms especially; nausea, vomiting, diarrhea, constipation and tiredness and psychological symptoms (nervousness, irritability, crying, happiness and return to normal psychological condition). This relief continued from the first to the third month. Exercise and acupressure therapies followed TENS therapy in symptoms relieving.

Meanwhile, after the application of the three techniques the present study showed a significant improvement in students' daily activities in the three study groups. This improvement was strongly observed in TENS group especially at the third month. This finding agrees with Shaban
$(2011)^{(17)}$ who found a significant improvement in daily activities of the students in three study groups and the highest improvement was observed with TENS group. On the other hand the present study disagrees with Ali $(2004)^{(14)}$ who had demonstrated that the most improvement of daily activities was noticeable after application of herbal group especially at the third month rather than exercise or TENS therapy .

The present study also revealed that, there was a statistical significant relation between the severity of pain and the use of the three techniques for relieving dysmenorrhea. The most improvement in the reduction of the severity of pain was marked in exercise and TENS group after third month .As the majority of the students had a heavy and unbearable pain before the program and this pain was completely abolished after the third month of the application.

During TENS application, the pain scores were significantly lower in the experimental group using visual analogue scale. Also, the present study agrees with Fawaz (2000) ${ }^{(22)}$ who mentioned that the severity of pain among the students at the High Institute of Nursing, Cairo University 
was significantly decreased after the application of TENS therapy and with Milne (2005) ${ }^{(23)}$, who added that, TENS was effective in the treatment of chronic low back pain in randomized controlled clinical trials of TENS for treatment: This might be due to the fact that TENS is a technique which leads to decrease muscle tension and peripheral blood flow which lead to a decrease in transmission of pain stimuli in the first order neuron.

Regarding the duration of menstruation, the present study found that students in the exercises group achieved the highest reduction regarding the duration of menstruation among the three study groups at third month of application. They also, had the duration of $2-3$ days $(8.0 \%)$ before application and reached $74.0 \%$ after the third month of application. Moreover the TENS group achieved the highest improvement regarding the light amount of blood loss $(96.0 \%)$ at third month of application. As for the type of blood loss, it changed to fluids in $92.0 \%$ of the students, with no clotted blood in the TENS group. Differences observed were statistically significant $(\mathrm{P}=<0.05)$.

\section{Conclusion}

In the light of the main study findings, it can be concluded that the prevalence of primary dysmenorrhea among students at Zagazig Technical Health Institute was $71.0 \%$. Complementary therapy was one of the effective and non pharmacological methods for reducing pain intensity. Using complementary therapies (exercise, TENS and acupressure) with the study groups have lead to the minimization of physical and psychological symptoms associated with dysmenorrhea and a significant reduction in primary dysmenorrheal intensity, duration of menstruation, amount of blood loss, change in type of blood loss, with improvement of its effect on daily activities and absenteeism.

\section{Recommendation}

Based on the findings of this study, the following recommendations are proposed:

1. Adolescents friendly clinic

Should be established in Schools, Institutes and Universities to enable students to easily seek help regarding menstruation and menstrual pain.

2-Complementary therapies should be an integral part of nursing education in Faculties and Technical Institutes. 
3. Complementary and alternative therapies should be more widely used and recommended by health care providers.

4. More research is needed for evaluation of the cost -benefit and cost effectiveness of complementary therapies for relieving dysmenorrheal pain.

\section{References}

1-French, L. Dysmenorrhea. Am Fam Physician. 2005; 71:285-291.

2-Lethaby, A. Augood, C. Duckitt, K. and Farquhar, C. Nonsteroidal anti-inflammatory drugs for heavy menstrual bleeding". Cochrane Database Syst Rev; 2007; 17 (4): 400.

3-Chantler, I., Mitchell, D. and Fuller, A. "The effect of three cyclo-oxygenase inhibitors on intensity of primary dysmenorrheic pain". Clin J Pain; 2008; 24 (1): 39-44.

4-Lloyd, K.B., and Hornsby, L.B. Complementary and alternative medications for women's health issues. Nutr Clin Pract. 2009; 24(5):589-608.

5-Ioron, V. Bianchini, B., Minelli, E. and Martinelli, F. Acupunctuer treatment of dysmenorrhea resistant to conventional medical treatment. Altern Med; 2007; 20:1-3.
6-Vrbová ,G., Hudlicka, O., Schaefer,

Centofanti, K."Application of Muscle/Nerve Stimulation in Health and Disease". Springer. Available at http://www.springer.com/medicine/bo2008 1978-1-4020-8232-01. Access date at 12/7/2011.

7-Tugay, N., Akbayrak, T. Demirturk, F. Effectiveness of transcutaneous electrical nerve stimulation and interferential current in primary dysmenorrheal “. Pain Med 2007; 8(4): 295-300.

8-Smith, H. J., Morkved, S. and Fairbrother, K. A. Pelvic floor muscle training for prevention and treatment of urinary and fecal incontinence in antenatal and postnatal women. Cochrane Database Syst. Rev. 2008;8 ( 4): 7471.

9-Guyton, A. and Hall, J. Textbook of Medical physiology $.11^{\text {th }}$ ed.London: Elsevier \& Saunders Co.2006; 590-609.

10-Campbell Department of Health and Human Service Public Health Service Clinical Practice Guideline. Publication .Rochvill, M.D.Agency for Heath Care Policy and Research; 2006;92-0032.

11-Hassin, N. Physical measures to relieve primary dysmenorrhea .High Institutes of Nursing, Mansoura University, Doctorate 
degree; 2002;104-111-13.

12-Bhan, N.B., Mahajan, P. and Sondhi, M. Awareness Regarding Sex Knowledge Among Adolescent Girls (16-20 years). Anthropologist; 2004; 6 (2): 101-103.

13-Singh, A., Klran, D. Singh, H., Nnel, B., Singh,P. and Tiwari, P. Prevalence and severity of dysmenorrhea: A problem related to menstruation, among first and second year female medical students. Indian J Physiol Pharmacol; 2008; 52 (4): 389-97.

14-Ali, H. Alternative therapies for relieving dysmenorrheal Pain A comparative Study .Faculty of Nursing El Menia University; 2004

15-Polat, A., Celik, H., Gurates, B., Kaya, D., Nalbant, M. and Kavak, E. Prevalence of primary dysmenorrhea in young adult female university students. Arch Gynecol Obstet.; 279(4):527-32.

16-Unsal, A., Ayranci, U., Tozun, M., Arslan, G. and Calik, E.: Prevalence of dysmenorrhea and its effect on quality of life among a group of female university students. Upsala Journal of Medical Sciences; 2010;115: 138-45.

17- Shaban, E. R. Comparative study between three different Techniques on relieving dysmenorrhea among students of
Faculty of Nursing at Tanta University 2011; 103 -30.

18-Abd El-Hameed, A.N, Maher, S., Mohamed, N. H., and Ahmed, E.R. Assessment of Dysmenorrhea and $\backslash$ Menstrual Hygiene Practices among Adolescent Girls in Some Nursing Schools at EL-Minia Governorate, Egypt. Obstetrics \& Gynecological Medicine Dept., Faculty of Medicine, Journal of American Science; 2010; 7(9):168-176.

19- Tangchai, K. D., Titapant, V. D. and Boriboonhirunsarn,D. Dysmenorrhea in Thai Adolescents: Prevalence, Impact and Knowledge of Treatment. Department of Obstetrics and Gynecology, Faculty of Medicine Siriraj Hospital, Mahidol University .J Med Assoc Thai ;2004; 87(3):69-73.

20-Wilson ,M.L \& Murphy ,P .A:Herbal and dietary therapies for primary and secondary dysmenorrheal .Cochrane Library Cochrane-data base -systRev;2002; (3)7: 10,61-63,81-89

21-Lemcke, D., Marshall, L., Pattison, J., and Cowlely, D. Current care of women: diagnosis \&treatment .United States of America, McGraw-hill Companies; 2004; 471. 
22-Fawaz, M. Comparative study of the effect of TENS and counseling on menstrual pain among females with primary dysmenorrhea receiving medications .High Institute of Nursing ,University of Cairo, thesis for partial fulfillment of doctorate degree 2000;140. 23- Milne, S., Welch, V., Brosseau, L., Saginur, M., Shea, B., Tug well, P. and wells, G. Transcutaneous Electrical Nerve Stimulation TENS for chronic low back pain .University of Ottawa, Faculty of Health Science ,Cochrane Database;2005; (2) 44-46. 